survey has now been published as Rheological Research in Britain, 1964*. It presents the information obtained by sending out nearly 600 copies of a questionnaire, and the replies give a clear picture of the very large amount of research in progress. Although only a few lines are devoted to each project, the survey runs to more than a hundred pages, being, in fact, the longest report so far published by the National Engineering Laboratory.

In this survey, a total of 226 establishments are listed, divided fairly evenly between universities, Governmentowned and Government-aided institutions, and industrial laboratories. There is an index of these establishments and another of the individual research workers. A third index, devoted to materials under investigation, shows the extremely wide range of present-day rheology. It runs through from adhesives to zirconium, via bananas and barytes, coke and eream, earth and eggshells, glaciers and graphite, mud and muscle, plutonium and pesticides, semen and sewage, wheat and wood, and a hundred other substances. The tabulated information has been analysed, and a series of histograms shows the distribution of interest between materials, between phenomena, between methods of approach and between processes. The first of these shows, for example, the predominant interest of industry

* Department of Scientific and Industrial Research: National Engineering Laboratory. Report No. 165: Rheological Research in Britain, 1964. (A Survey made jointly by the British society of Rheology and the National Engineering Laboratory.) By A. Y. McLean and A.T. J. Hayward. Pp. $\mathrm{i}+103$. (East Kilbride, Glasgow: National Engineering Laboratory, 1964.) in polymers and multi-phase materials, while university interest is more generally distributed with some concentration on idealized materials. On the other hand, the interest. in phenomena displayed by the universities runs nearly parallel with the industrial interest, although the latter is rather more concentrated on the non-Newtonian viscosity of liquids and the former on the plasticity of solids. Of the methods of approach, that of continuous shear viscometry and rheometry is the most generally used, but this is closely followed by theoretical methods and then by tensile and compressive testing. The extent of the industrial interest. in the theoretical approach is quite remarkable, being equal to that shown by the universities. Another surprising feature is the smallness of the interest shown by industry in individual processes (such as extrusion, mixing, flow through pipes and channels) in comparison with the interest in fundamental phenomena.

The present survey is necessarily incomplete, and it would seem that the coverage is weakest in biology and in the study of metals. It is hoped that it will become a regular publication, and the compilers ask that anyone whose work has been overlooked should inform them so that it may be included in the next edition. In this way the survey should become a really comprehensive guide to those who may wish to seek specialized advice and to those who are concerned with the initiation of new research projects with industrial applications.

R. Roscot

\title{
FAMILIAL TRENDS OF CANCER
}

$\mathrm{S}^{\mathrm{n}}$ INCE January 1960, the New South Wales State $S$ Cancer Council has been conducting a survey of women treated for cancer of the breast in order to determine whether there is a higher incidence of cancer among the relatives of this group than among the relatives of a control group of the same size presumed not to be suffering from cancer. The survey is a sequel to many investigations of hereditary and familial trends of cancer which have been mado in Europe, Britain and the United States during the twentieth century.

In the course of the survey carried out by Pamela Siddins*, each of 99 female patients with broast cancer and each of the 99 other women who formed the control group supplied a history of her family. The incidence of cancer among the siblings, parents, aunts, uncles, cousins and grandparents of the women in each group was determined from hospital records and from the cause of death entered on death certificates. A questionnaire was devised, which sought information concerning the age, marital status, geographical situation, socio-economic position, lactation, order of birth, and menstrual and fertility history of patients and control probands.

Incidence of cancer in family histories was taken as that existing at the time of interview. The ages of the patients included in the survey ranged from 33 years 6 months to 74 years 8 months; these consisted of 84 married women with children, 10 married women without children, and five unmarried women. Of the total number of women interviewed, only about 33 per cent were included in the survey. There were many reasons for unsuitability of probands, the chief reason being the fact that fow families had lived in Australia for the required three generations. Many who thought that all their grandparents had died in Australia were later excluded from the survey when official records proved otherwise. It was soon realized that the original plan, which had been to locate all relatives back to great-grandparents, would be impracticable.

At first, the findings suggested that breast and other types of cancer occurred more often in the families of the

* New South Wales State Cancer Council Publication No. 9. patients with breast cancer than in those of the control probands. For analysis, the types of breast cancer encountered in the survey were divided into the following basic classes: scirrhous, encephaloid or medullary, mucous or colloid, adeno- and duct carcinoma, sarcoma, and Paget's disease of the breast. For 12 patients no histological reports were available, because of loss of records or because no biopsy (or other diagnostic surgical measure) had been performed. Adenocarcinoma and scirrhous carcinoma were the types most frequently encountered. The breast cancer probands included three twins, two belonging to a dizygotic pair and one to a monozygotic pair, but in none of the twins of these patients was there evidence of cancer. No case of cancer of the breast in males was encountered among the relatives of the probands. It occurred, however, in sisters of breast cancer probands in five families and in mothers of three probands.

Cancer occurred less frequently in similar relatives of the control probands. Controls interviewed at medical clinies were not aware that the survey was concerned with the incidence of any one disease. Patients and controls from cancer detection clinics, when asked for the illnesses and operations known in three generations of relatives, tended to emphasize the cancers rather than other diseases. Most frequently the incidence of cancer was incorrectly given by the proband-the number of cancers being exaggerated in those families where several cases were known, and underestimated in families whose attention had never been directed to it for any reason.

The information collected was analysed statistically by $S$. Chorlton, who found that the number of relations per cancer proband ranged from 18 to 190 , with a mean of 70.5 . Of these, the mean number for whom some reliable medical history was known was 50.8 , or 72.1 per cent. For the controls, the average number of relations was 62.4 (range 14-127), of whom medical history was known for 48, or 77 per cent. The number of relatives with some documented medical history amounted to 5,042 (cancer group) and 4,753 (control group). Some form of cancer occurred in 87 out of the 99 families of patients with the disease- 
breast cancer being found in $\mathbf{2 1}$ of these. For the controls, cancer occurred in a total of 80 families, with an incidence of breast cancer in 13 .

There is a notable absence of any significant infant mortality rate due to cancer, attributable probably to poor diagnosis in earlier times. Mortality in the early agegroups, particularly in the $0-4$ years age-group, is high, but, of 819 deaths of relations for both cancer and control groups, only one death from cancer is reported. This was reflected in a general reduction in the incidence of all cancers in both groups.

The mean age for detection of cancer of the breast in the proband is 47.5 years, and for those families with breast cancer in relatives it is 48.4 years. The mean ages for patients and control groups at the time of the survey were $50 \cdot 1 \pm 13 \cdot 6$ years (cancer group) and $50 \cdot 4 \pm 10 \cdot 3$ years (control group). This means that the cancer group has, on the average, lived $2 \cdot 6$ years since the diagnosis of their disease.

The number of cases of cancer and the types of cancer occurring in the two groups show a similar distribution, except for breast cancer. The highest rate for breast cancer among relatives occurs in maternal aunts. There is a higher incidence of breast cancers and all cancers in female relations of breast cancer patients. With regard to the effect of degree of relationship, there is a high incidence of breast cancer in persons with a coefficient of relationship of one-quarter in the patient group.

\section{EPILEPSY IN AFRICANS}

A STUDY of epilepsy in Africans in Southern Rhodesia has been undertaken by Dr. L. F. Levy, Dr. J. I. Forbes and Dr. T. S. Parirenyatwa of Harare Hospital, Salisbury, Southern Rhodesia (Central African Journal of Medicine, 10, No. 7; July, 1964). In a field survey carried out in the Semokwe Reserve, 130 persons admitting to seizures were discovered in a population of approximately 17,500 , and these sufferers were interviewed. A parallel group of 100 patients presenting at Harare Hospital with the complaint of seizures was also fully investigated.

The incidence of epilepsy in Africans is probably slightly higher than in Europeans, but African patients tend to present themselves for treatment only when their earning capacity becomes threatened by the disorder. Fits affecting women and children seem to be regarded by patient and parent alike as a misfortune to be accepted, and there must be large numbers of rural sufferers who have never sought medical help. Even allowing for this tolerance of fits, however, the discrepancy between the number of males (161) and females (69) in the combined study seems remarkable and contrasts strongly with the sex distribution reported by other authors.

The age of onset of the disease is similar to that found in other racial groups. Premonitory symptoms vary widely and have no special characteristics. The frequency of attacks in the rural group is interesting because it reflects the pattern of epilepsy which is uncontrolled and allowed to run its natural course. About 10 per cent of the sufferers in the Semokwe Reserve group had fits once a day or more; another 10 per cent had fits several times a month; more than half (56 per cent) had fits once or twice a month, and the remaining 24 per cent had them at intervals of once in two months or longer. A family history of fits was obtained from 65 per cent of the sufferers in the Semokwe Reserve group, but only from 20 per cent of those in the
Harare Hospital group. The question of genetic factors in epilepsy should be re-evaluated in all races.

Accidents resulting from fits are common. Twenty-one per cent of the field group and 19 per cent of the hospital group had sustained burns at some time, and, in many cases, the deformity resulting from these was severe. Apart from the physical trauma, epilepsy has a marked effect on the life of the sufferer. In the Semokwe Reserve group 39 per cent of the children up to the age of 14 years were made the butt of humour, and 44 per cent of patients over the age of 15 years were made to feel outcasts by the rest of the community. Twelve male adults and one female had been dismissed from their jobs on account of their seizures. The effects of epilepsy on marital life seem to have no special peculiarities.

Enquiries into tribal beliefs about the ætiology of epilepsy reveal how widespread is superstition and to what extent belief in witchcraft persists. Fifty-nine per cent of Semokwe Reserve sufferers believed their epilepsy resulted from their being 'bewitched'.

The present treatment of epilepsy in such patients is frequently unsatisfactory. The standard anti-convulsant. drugs are as effective in controlling their fits as in other races, but, in the first place, sufferers do not make themselves available for treatment; and, secondly, even if they do, the problem of achieving regular and conscientious administration of the selected drug remains. This was also the finding of Hurst et al. in the Meadowlands survey. Education and enlightenment of rural Africans will, no doubt, eventually change their present attitude of resignation. In the meantime, it seems that the only way to reach the sufferers would be to send mobile teams into the reserves to seek them out. Once the diagnosis has been made and curable underlying disease excluded, treatment with a long-acting injectionable anti-convulsant would appear to offer the best hope of adequate control.

\section{RECENT REVIEWS OF FOSSIL FISHES}

$\mathrm{T}$ WO publications of special interest have recently been published on fossil fish: Dr. R. H. Denison has reviewed the Cyathaspididae*, and Dr. C. Patterson $\dagger$ the Mesozoic Acanthopterygia.

Dr. Denison deals with the earliest known family of Agnatha, excluding isolated fragments from earlier strata.

* Chicago Natural History Museum. Fieldiana: Geology. 13, No. 5 : The Cyathaspididae - a Family of Silurian and Devonian Jawless Vertehrates. By Robert H. Denison. Pp. 309-473. (Chicago: Chicago Natural History Museum, 1964.) 5 dollars.

+ Philosophical Transactions of the Royal Society of London. Series B Biological Sciences. No. 739, 247 (July 2, 1964): A Review of Mesozoic A canthopterygian Fishes, with special reference to those of the English Chalk.
By C. Patterson. Pp. 212-482 + plates 2-5. (London: Royal Society, 1964.) 105s. 15.75 dollars.
The material ranges from the base of the Middle Silurian (Wenlockian) to late Early Devonian (Dittonian). The author describes the anatomy, external and internal, of all forms, which comprise in his interpretation 63 species grouped into 19 genera. The classification adopted for the Cyathaspididae is essentially that of other recent writers, allowing for shifts in the hierarchical status of the taxa. Dr. Denison follows most scholars, Stensiö excepted, in dissociating the Heterostraci from close affinity with the cyclostomes, osteostraci and anaspids. He divides the class Agnatha into two sub-classes, the more primitive Diplorhina with Heterostraci and probably Coelolepida, and the more specialized Monorhina with Myxinoidea and 